\title{
Non-pharmaceutical Interventions for Hypertrophic Cardiomyopathy: A Mini Review
}

\author{
Miaomiao $\mathrm{He}^{1}$, Jie Qiu ${ }^{1}$, Yang Bai ${ }^{1}$, Yan Wang ${ }^{1}$, Mei Hu ${ }^{2 *}$ and Guangzhi Chen ${ }^{1 *}$ \\ ' Division of Cardiology, Department of Internal Medicine, Tongji Hospital, Tongji Medical College, Huazhong University of \\ Science and Technology, Wuhan, China, ${ }^{2}$ Health Management Center, Tongji Hospital, Tongji Medical College, Huazhong \\ University of Science and Technology, Wuhan, China
}

\section{OPEN ACCESS}

Edited by: Alexander Pott,

Ulm University Medical Center, Germany

Reviewed by:

Dominik Buckert,

Ulm University Medical

Center, Germany

Nazareno Paolocci, Johns Hopkins University,

United States

*Correspondence: Guangzhi Chen chengz2003@163.com

Mei Hu

icehumei@126.com

Specialty section:

This article was submitted to Cardiovascular Genetics and Systems

Medicine,

a section of the journal

Frontiers in Cardiovascular Medicine

Received: 28 April 2021

Accepted: 20 September 2021

Published: 15 October 2021

Citation:

He MM, Qiu J, Bai Y, Wang Y, Hu M and Chen GZ (2021)

Non-pharmaceutical Interventions for Hypertrophic Cardiomyopathy: A Mini

Review.

Front. Cardiovasc. Med. 8:695247.

doi: 10.3389/fCvm.2021.695247
Hypertrophic cardiomyopathy is an inherited cardiovascular disease, and $70 \%$ of patients have left ventricular outflow tract obstruction. Ventricular septal myectomy has been the gold standard treatment for most patients with refractory symptoms. Due to higher mortality associated with medical facilities with less experience, alcohol septal ablation has been accepted as an alternative to conventional surgical myectomy. It offers lower all-cause in-hospital complications and mortality, which could be potentially more preferable for patients with serious comorbidities. In recent years, radiofrequency ablation, providing another option with reproducibility and a low risk of permanent atrioventricular block, has become an effective invasive treatment to relieve left ventricular outflow tract obstruction. Moreover, substantial progress has been made in gene therapy for hypertrophic cardiomyopathy. The principal objective of this review is to present recent advances in non-pharmaceutical interventions in hypertrophic cardiomyopathy.

Keywords: hypertrophic cardiomyopathy, radiofrequency catheter ablation (RFCA), alcohol septal ablation, sudden cardiac death, next-generation sequencing

\section{OVERVIEW OF HYPERTROPHIC CARDIOMYOPATHY}

Hypertrophic cardiomyopathy (HCM) is a hereditary cardiomyopathy. Epidemiological studies have shown that the prevalence in the general practice population is 1 in 500, but the rates are higher (1 in 200) if the genetic diagnosis is considered (1-3). Seventy percent of patients have hypertrophic areas involving the anterior ventricular septum and the basal segment of the anterior wall. Moreover, $70 \%$ of patients have mechanical impedance of the left ventricular outflow tract obstruction (LVOTO) (gradient $\geq 30 \mathrm{mmHg}$ ) in the resting or moving state, causing systolic anterior motion (SAM) of the mitral valve $(4,5)$. Recently, it has been reported that discrete subaortic membranes can cause LVOTO with or without SAM, which can be treated only with surgical intervention (6).

The clinical manifestations of HCM are non-specific and diverse, which may result in a series of symptoms, including exertional dyspnea, fatigue, palpitations, dizziness, syncope, atypical chest pain, and sudden cardiac death (SCD) caused by ventricular obstruction $(3,7-9)$. Despite using the maximal pharmacologic dose and having no mitral valve and/or papillary muscle abnormalities, some patients with HCM still have obvious clinical symptoms; thus, approaches such as alcohol septal ablation (ASA) and ventricular septal myectomy (VSM) were recommended for these patients. Moreover, the role of radiofrequency catheter ablation (RFCA) in septal reduction therapy for HCM is increasingly being valued by interventional physicians in recent years. However, the choice of invasive treatment for patients with seemingly intermediate symptoms remains a debatable topic (Figure 1). 


\section{patients with HOCM}

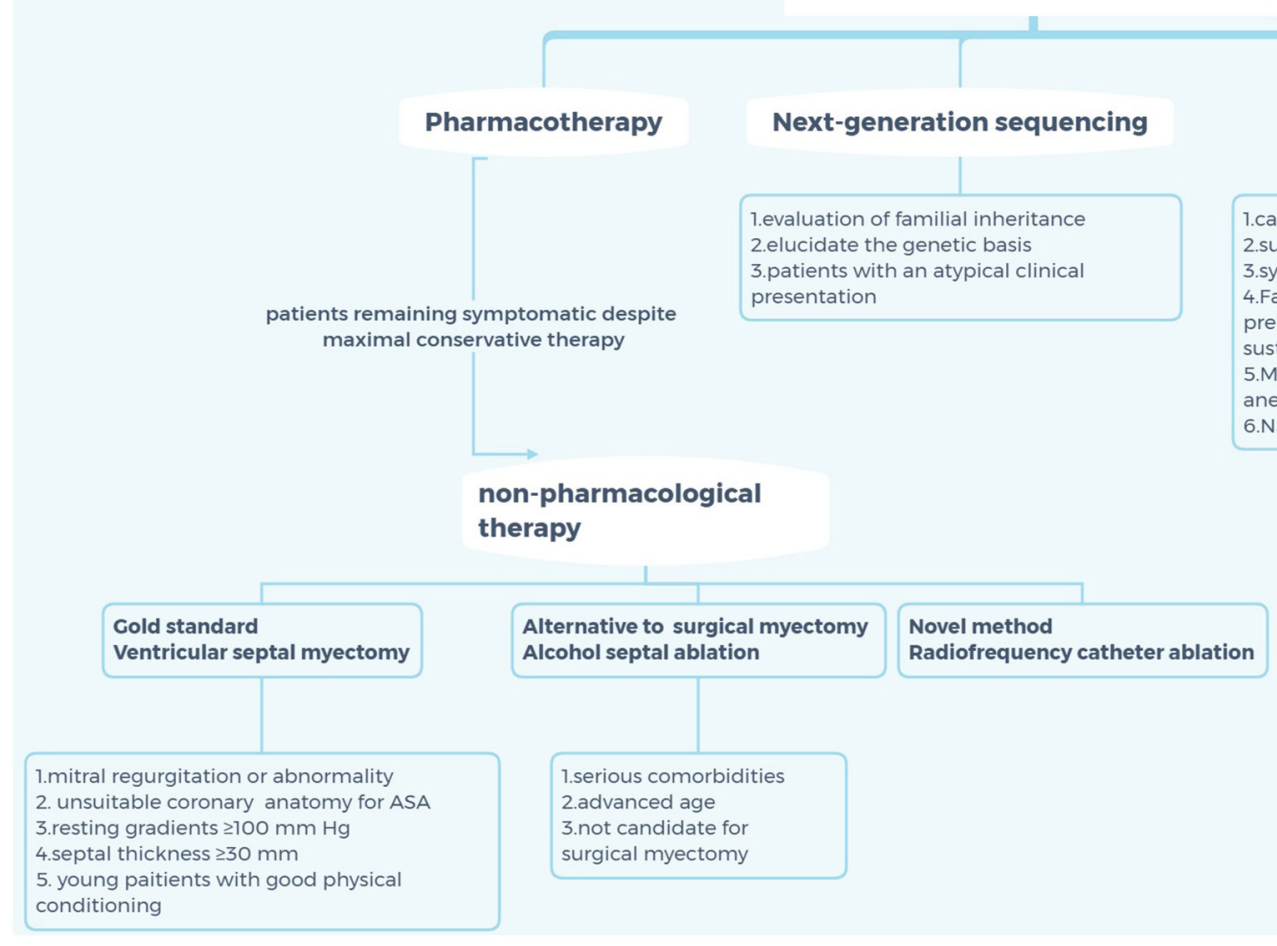

FIGURE 1 | Criteria for selection of non-pharmaceutical interventions for patients with hypertrophic cardiomyopathy. HOCM, hypertrophic obstructive cardiomyopathy; SCD, sudden cardiac death; HCM, hypertrophic cardiomyopathy; EF, ejection fraction; LV, left ventricle; NSVT; non-sustained ventricular tachycardia; ASA, alcohol septal ablation.

\section{LIFESTYLE MODIFICATIONS}

Persuading individuals with confirmed HCM to abandon competitive sports is a simple but effective way to decrease the incidence of SCD (10). However, exercise may directly improve diastolic dysfunction, as evidenced by electrocardiogram (ECG) findings and endothelial function, which are essential for regulating microcirculation $(11,12)$. In addition, there is scientific evidence that moderate-intensity exercise increases the exercise capacity in patients with HCM (13). Notably, the 2020 American College of Cardiology/American Heart Association (ACC/AHA) guidelines have encouraged patients with HCM to perform mild- to moderate-intensity recreational exercises to improve cardiorespiratory fitness.

\section{RELEASE OF THE OBSTRUCTION}

\section{VSM}

For decades, septal myotomy, which involves the removal of a relatively small amount of muscle from the ventricular septum, has been the gold-standard treatment for most patients with HCM (14-16). Septal myectomy associated with mitral valve repair or replacement is an effective method for patients with HCM with severe mitral regurgitation (MR) or abnormality (17-
21). However, the physiological function of the mitral valve cannot be preserved with mitral valve replacement and a clinical trial involving 2,107 cases showed that simple elimination of left ventricular outflow tract (LVOT) could reverse MR in $98 \%$ of patients $(22,23)$. What is even more remarkable is that almost all patients undergoing surgical resection will have left bundle branch block, and the mortality rate in small medical institutions is higher than that in large and experienced institutions. In a systematic study in 2003-2011, medical facilities with less experience were associated with higher mortality, longer hospital stays, and higher expenses (24). The advantages of myectomy are not matched by other minimally invasive procedures and drug therapy in cases of intrinsic abnormalities of the mitral valve, such as ruptured chordae tendinae or coexisting calcific or rheumatic mitral valve disease (25).

\section{ASA}

Currently, ASA techniques have developed considerably, and ASA is accepted as an alternative to conventional surgical myectomy $(26,27)$. There is a large body of evidence that both procedures improve functional capacity, and there is no difference between ASA and VSM with regards to long-term all-cause mortality, cardiovascular mortality, or $\operatorname{SCD}(28,29)$. The results of a large observational analysis of outcomes after 
ASA vs. VSM in patients with HCM suggested that ASA is associated with significantly lower all-cause in-hospital mortality and in-hospital complications and a higher rate of ventricular tachycardia, suggesting that ASA could be a better treatment procedure with fewer complications (30).

The selection criteria for ASA are generally based on anatomical features and increased operative risk advising against surgery. Not all patients with ventricular septal vascular anatomy are suitable for ASA. In 5\%-15\% of patients with HCM, ASA cannot be performed due to unsuitable coronary circulation anatomy and the presence of multiple submillimeter septal branches that are not accessible to the necessary armamentarium $(31,32)$. Invasive coronary angiography perioperatively assesses the information about the course and size of the coronary arteries and septal branches to determine whether the endovascular approach was adequate for ASA. Pre-procedural ECG-gated multidetector computed tomography imaging provides an advantage in localizing the appropriate septal branch by significantly diminishing the number of approached target vessels and non-ablated target vessels (33). It then provides a three-dimensional volume-rendering image of the coronary arteries and a two-dimensional image of the myocardium in diastole for the assessment of the spatial relationship between the septal branches and the target myocardial territories. Thus, the target septal artery could be selected, and the feasibility of ASA could be determined.

Pre-surgical implantation of temporary pacemaker has been suggested in patients undergoing ASA because up to $25 \%$ of these patients will have acute or subacute heart block and even require the implantation of a permanent pacemaker $(34,35)$. As expected, the rate of atrioventricular block requiring permanent pacemaker implantation was higher in younger patients (age $\leq 55$ years) (36). Except for age, pre-ASA left bundle branch block, transient procedural high-grade block, post-ASA PR prolongation ( $\geq 68 \mathrm{~ms}$ ), and new bifascicular block also were also predictors of complete heart block. These factors are reported to be important components of an 11-point clinical prediction tool, which thus allow the identification of high-risk patients who may benefit from additional monitoring and therapy (37). At present, the risk of ventricular tachyarrhythmia after ASA remains controversial. Alcohol inadvertently leaking from the target vessel could cause severe and extensive myocardial necrosis (38). Scars and islands of viable tissue after ASA are intertwined, which may cause arrhythmia (39). In a recent multicenter European study, appropriate implantable cardioverter defibrillator (ICD) shocks for ventricular tachycardia or fibrillation were eight-fold more common after ASA than after VSM (40). Notably, current monitoring following ASA using an implantable cardiac monitor could uncover clinically actionable events. A study followed up 56 patients with implantable cardiac monitor for 18 months, and the results showed that the overall cumulative rate of arrhythmic events was higher than that previously reported and that the most common arrhythmias following ASA were complete heart block and atrial fibrillation. However, whether ASA has a pathophysiological association with future development of atrial fibrillation is unknown. In this patient cohort, the cumulative rate of complete heart block detected by the implantable cardiac monitor within 18 months was $19 \%$, which was mostly due to the injection of alcohol into septal perforators, resulting in injury to the His-Purkinje conduction system (41).

In August 2020, the ACC/AHA has released guidelines for the treatment of HCM, indicating that ASA may be less effective with high resting gradients $(\geq 100 \mathrm{mmHg}$ ) and severe septal thickness $(\geq 30 \mathrm{~mm})$, and a study showed that the long-term all-cause and cardiac mortality rates in a 5-year follow-up are worse in patients with severe septal thickness $(\geq 30 \mathrm{~mm})(3,42)$. As a consequence of these indications, ASA is potentially more preferable for patients with significant comorbidities that increase the risk of surgical myectomy, as the discomfort associated with surgery is avoided and the recovery time is reduced. Furthermore, the midand long-term arrhythmogenic potential of septal ablation needs to be appreciated, especially in older patients or those who, for different reasons, are not candidates for surgical myectomy.

\section{RFCA}

RFCA, which is used to treat arrhythmia, has evolved over the last 20 years and features the formation of a high impedance on the surface of the myocardium and blockade of abnormal conduction of myocardial cells by high temperatures. Theoretically, radiofrequency (RF) energy can also be used to create myocardial injury in the ventricular septum to alleviate LVOTO. In recent years, the progress of methods, such as highpower and short-time ablation, active electrode cooling by saline irrigation, amplitude control ablation technology, and bipolar ablation technology, has made it feasible to create continuous lesions (43-49). Thus, treatment based on RF could be efficacious and has a longer-lasting effect.

Can RF be applied in the treatment of HCM? In 2004, Lawrenz and Kuhn (50) first reported a case of HCM treatment using $\mathrm{RF}$. In this report, the patient was given procedural stimulation and marking of the His bundle using the Prucka mapping system. Then, $40 \mathrm{RF}$ pulses were delivered to the right ventricular septum in a septal area of approximately $1 \mathrm{~cm}^{2}$. After resting and excitation, the LVOT gradient was significantly reduced. Even more surprising, the SAM symptom disappeared. This team further recruited 19 patients with HCM, and during these procedures, 14-40 RF pulses were delivered after marking the His bundle with a CARTO ${ }^{\circledR}$ catheter (Biosense Webster, Diamond Bar, CA, USA). According to the results, the LVOT gradient was reduced by $62 \%$ after resting and by $60 \%$ after provocation. Gadolinium-enhanced magnetic resonance imaging showed a late-enhanced area with a depth of $28 \mathrm{~mm}$ in the ablation area, but the thickness of the interventricular septum did not significantly decrease (51).

Some progress was made by Emmel and Sreeram (52), who performed RFCA in three children with HCM in 2005, two of whom had mitral valve malformations. Using the LocaLisa mapping system (Medtronic, Minneapolis, MN, USA) to mark the position of the His bundle, the operator performed ventricular septal ablation from the left ventricle through a retrograde and trans-aortic approach to generate three linear lesions between the left ventricular apical septum and the aortic 
valve. The LVOT decreased to $<20 \mathrm{mmHg}$ after 6 weeks and no complications occurred during the clinical follow-up.

In 2015, Shelke et al. (53) recruited five patients with HCM for RFCA. All patients were treated with the retrograde and trans-aortic approach using intracardiac echocardiography, the CARTO ${ }^{\circledR}$ system and EnSite NavX (Abbott, St. Paul, MN, USA) to mark the His bundle, left bundle branch, and Purkinje fibers during the operation. The ablation sites were the protruding parts of the ventricular septum in the transition area. It is worth noting that the ablation power and ablation time were reduced when the catheter moved close to the conduction system. After $1,3,6$, and 12 months of follow-up, the LVOT of most patients continued to decrease, and no patient had atrioventricular block. Crossen et al. (54) reported the results of RFCA of the left ventricular septum, selecting transseptal access to the left atrium. However, the retrograde transaortic approach was applied when patients had an extraordinarily narrow outflow tract. The thickest part of the ventricular septum, which would be damaged by 120 s of continuous 50W RF energy, was marked on the NavX system. The LVOT in the stimulating and resting states in most patients decreased continuously by $85 \%$ after 12 months and the New York Heart Association class increased by at least one level. Cooper et al. (38) reported the first RFCA guided by CARTOSound ${ }^{\circledR}$ (a combination of echocardiography and CARTO ${ }^{\circledR}$; Biosense Webster), in which lesions were placed over the SAM-septal contact area and the energy power was 50$60 \mathrm{~W}$ with a maximum temperature of $60^{\circ} \mathrm{C}$. The patient's resting LVOT gradient decreased $51.9 \mathrm{mmHg}$, the Valsalva or exerciseinduced gradient decreased to $70.2 \mathrm{mmHg}$, and the New York Heart Association class improved from III to II/I.

RFCA can produce predictable, discrete lesions, with a clear boundary between the scar and healthy surrounding muscles, which, in principle, can reduce the tendency of arrhythmia. The three-dimensional mapping system has been applied in RFCA to mark the heart conduction system and avoid damage as much as possible. A previous study showed that the incidence of conduction system damage could be reduced by decreasing the RF energy and time ablation. For a person who cannot choose ASA and has a contraindication for myectomy, RFCA provides another option with reproducibility and a low risk of permanent atrioventricular block. Although there was no recommendation in the guidelines, RFCA may be best for some patients with poor physical conditions and mildly thickened interventricular septum. In addition, repeated RFCA of the ventricular septum is feasible (54).

However, the use of RFCA in treatment of HCM is still under investigation and development, and many studies have provided evidence that RFCA increases the risk of abnormally increased LVOTO in HCM patients in the late-stage due to tissue edema, which needs to be considered preoperatively. In addition, adequate anticoagulation should be used during the operation, and minimum liquid flushing of the tip of the catheter and diuretics could avoid liquid overload, which can improve the safety of the operation. Prolonged operation of the left ventricular catheter may cause transient atrial fibrillation, and abnormal mitral valve papillary muscle attachment may play an important role in the occurrence of LVOTO, which should be carefully evaluated before surgery (for a summary of operation, see Table 1).

\section{Transcatheter Mitral Valve Repair}

In patients with HCM, LVOTO develops during left ventricular ejection in mid-systole due to SAM. The elongation and enlargement of anterior mitral leaflet and posterior mitral leaflet lengths, common in HCM patients, is an important morphological abnormality responsible for SAM syndrome (55). Transcatheter mitral valve repair, plicating the valve leaflets and preventing SAM of the valve, could offer a new treatment modality for the HCM patients. In 2017, Sorajja et al. (56) firstly treat the HCM patients using percutaneous mitral valve plication as a primary therapy. These patients are not optimal candidates for VSM due to their advanced age and frailty. In the postprocedural follow-up, the SAM of the valve and LVOT gradient of most patients was reduced, and symptom was improved by at least 1 New York Heart Association functional class without major adverse clinical events. Interestingly, Coylewright et al. (57) reported a case about HCM treatment using percutaneous edge-to-edge repair device. Transcatheter mitral valve repair with MitraClip (Abbott Laboratories, Abbott Park, IL, USA) was performed with one clip via a transseptal approach. At the postoperative evaluation, MR and SAM of the anterior mitral leaflet was reduced. Transcatheter mitral valve repair may be an effective therapy for patients with degenerative MR and concomitant LVOT obstruction. Further basic science research and eventual randomized clinical trials are needed to make claims of efficacy and safety for this novel treatment.

\section{SCD ASSESSMENT AND PREVENTION}

SCD affects at least $0.2 \%$ of the global population and is the most common cause of fatal ventricular arrhythmia in young people and athletes (58). The 2020 ACC/AHA guidelines combine several clinical markers into a risk stratification algorithm to identify populations at high risk who should promptly undergo ICD and other prevention programs that can effectively terminate ventricular tachycardia and fibrillation such as those with history of cardiac arrest, syncope suspected by arrhythmia, etc., (59-62). The SHIFT model may provide prognostic value for ICD implantation for the primary prevention of SCD (63). All patients with diagnosed or suspected HCM should be evaluated every 1-2 years, especially those who may be eligible for ICD indications (58). In 2013, O’Mahony C et al. (66) proposed the HCM Risk-SCD Calculator, a new HCM SCD clinical risk prediction model derived from a retrospective multicenter longitudinal cohort study, which lies in the shift from relative risk assessment to absolute risk assessment $(64,65)$. However, this model also has shortcomings; for example, it cannot be applied to pediatric patients or elite or competitive athletes younger than 16 years. Moreover, late gadolinium enhancement has emerged as an important predictor for SCD, and the incidence rate of SCD/aborted SCD in patients with HCM with positive late gadolinium enhancement is greater than that in patients with negative late gadolinium enhancement (67). 
TABLE 1 | Advantages and disadvantages of different operative management.

\begin{tabular}{|c|c|c|c|}
\hline & Ventricular septal myectomy & Alcohol septal ablation & Radiofrequency catheter ablation \\
\hline Advantages & $\begin{array}{l}\text { - Gold standard } \\
\text { - Treatment of mitral valve repair } \\
\text { or replacement }\end{array}$ & $\begin{array}{l}\text { - Lesser iatrogenic trauma } \\
\text { - Alternative to surgical } \\
\text { myectomy } \\
\text { - Shorter stay in the hospital } \\
\text { - Lower cost }\end{array}$ & $\begin{array}{l}\text { - Predictable lesions } \\
\text { - Avoiding damage to conduction } \\
\text { system } \\
\text { - Reproducibility }\end{array}$ \\
\hline Disadvantages & $\begin{array}{l}\text { - Relatively higher mortality rate } \\
\text { - Longer stay in the hospital } \\
\text { - Higher expenses }\end{array}$ & $\begin{array}{l}\text { - Limitation of vascular anatomy } \\
\text { - Occurrence of heart block } \\
\text { - Possibility of } \\
\text { myocardial necrosis }\end{array}$ & $\begin{array}{l}\text { - Risk of abnormally increased left } \\
\text { ventricular outflow tract obstruction } \\
\text { - Hemorrhage due to anticoagulation } \\
\text { - Occurrence of transient } \\
\text { atrial fibrillation }</ \text { List }>\end{array}$ \\
\hline
\end{tabular}

Patients with a risk of $4 \%$ in the HCM risk calculator and at least two major risk factors (left ventricular apical aneurysm or end-stage HCM) receive ICD treatment $(66,68)$. Moreover, a recent paradigm has suggested that ICD therapy responsible for a substantial decrease in overall HCM-related mortality is independent of patient age (69). It is imperative to make ICD decisions for younger HCM patients at high risk for SCD; however, it has low pacing probability (66). Additionally, there is no evidence that drug therapy has a protective effect against SCD caused by malignant ventricular arrhythmia in individuals with HCM (70). Therefore, the use of drugs to prevent SCD in asymptomatic patients with HCM is not recommended.

\section{GENE THERAPY}

HCM is an inherited disease and almost always results from mutations in multiple protein-coding genes, modulation by non-coding RNAs, and perturbations in gene networks. Approximately $35 \%-60 \%$ of patients carry pathogenic mutations in the autosomal dominant sarcomere protein gene, which is related to 1,400 mutations in more than 11 different genes (7175). Among these HCM genes, only 8 genes have definitive evidence of disease association (MYBPC3, MYH7, TNNT2, TNNI3, TPM1, ACTC1, MYL2, and MYL3), 3 genes have moderate evidence (CSRP3, TNNC1, and JPH2), and 22 have limited or no evidence (TTN, KLF10, MYPN, etc.) (Figure 2) (76). Current research has found that Filamin C (FLNC) plays a prominent role in HCM. The dysfunction of FLNC could interfere with the dimerization and folding of the protein, leading to aggregate formation, which is detrimental to muscle function, as found in HCM. In addition, pathogenic mutations in the sarcomere genes MYH7 and MYBPC3 explain 60-70\% of observed clinical cases, and they could exist in biallelic inheritance or more complex variants, including CNVs and de novo mutations (77).

Compared with familial HCM, individuals with non-familial HCM have late-onset and less severe disease (78-80). The correlation between genotype and phenotype is not consistent because of the complex genetic basis, epigenetics and other mechanisms for regulating gene expression, environmental conditions such as non-sarcomere genetic variations, and more importantly, the overlap among several disease gene groups (81-85). These factors make genetic testing and result interpretation particularly challenging.

Next-generation sequencing (NGS) is an effective method for measuring and analyzing gene mutations in HCM (86). The 2020 ACC/AHA guidelines recommended next-generation sequencing for diagnosing HCM, suggesting that cascade screening should be performed in family members at risk in order to prevent or treat appropriately $(3,87)$. Periodic examination with echocardiogram and ECG is encouraged for all first-degree family members (88); meanwhile, individuals with negative genotypes do not need routine ECG or echocardiogram (68, 81). In a retrospective analysis of adult and pediatric splotch mutation carriers identified during family screening, results showed that approximately $50 \%$ of splotch mutation carriers develop HCM over 15 years and that independent predictors of HCM development were male sex and abnormal ECG (89). This study indicates that the timing of follow-up could be tailored to the splotch mutation carriers, male sex, and abnormal ECG, rather than age. Whole-genome sequencing could identify gene variants in $9 \%$ of HCM with negative next-generation sequencing results, which also had shortcomings in discovering a large number of variants of uncertain clinical significance $(90,91)$. Moreover, multiple gene variants have been identified in $0.4 \%$ of the patients and are correlated with adverse cardiac events $(92,93)$. Children with a positive phenotype are at greater risk of serious clinical manifestations and cardiac events and clinical screening at an earlier age is currently recommended $(94,95)$.

Gene therapy could be considered, particularly genome editing, exon skipping, allele-specific silencing, and RNA transsplicing, most of which are in the stage of molecular research or animal experimentations. Successful gene replacement with the delivery of functional MYBPC3 cDNA mediated by adenoassociated vector 9 in human cardiomyocytes derived from embryonic stem cells proved that gene replacement is a feasible therapeutic option (96). Adenovirus vectors with high safety and feasibility have been proven in published studies and are frequently used as carriers; meanwhile, genetic correction using CRISPR technology eliminates the electrophysiological abnormalities in the patient's induced pluripotent stem cells $(97,98)$. With these advances, gene therapy could be a viable treatment option for HCM, especially for its severe forms.

In summary, research on HCM has made great progress in recent years; nevertheless, some questions and challenges remain 


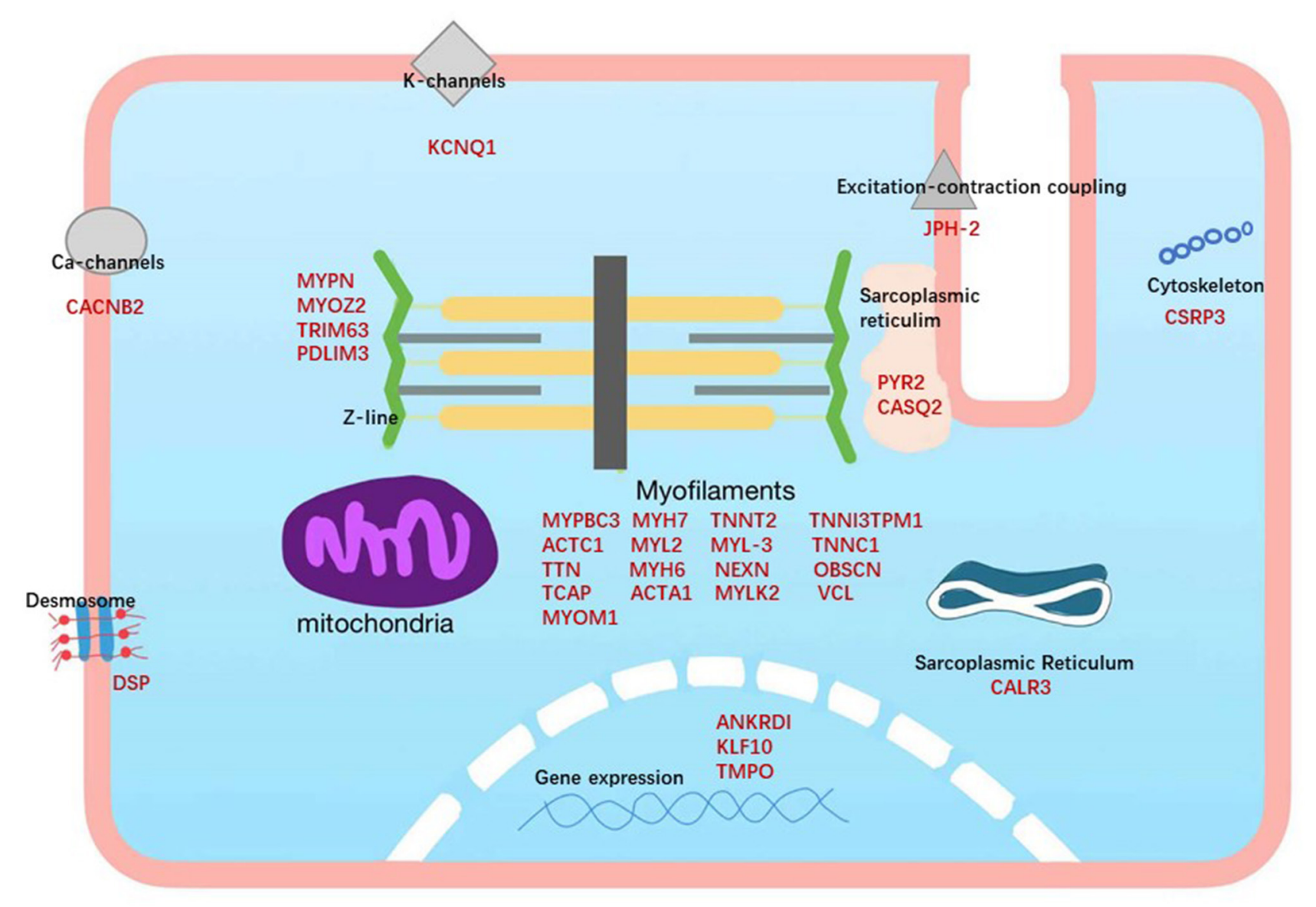

FIGURE 2 | Subcellular locations of the proteins encoded by the genes associated with hypertrophic cardiomyopathy. HCM genes are shown in red.

to be solved by further research. After decades of continuous efforts, ASA has been accepted as an alternative to conventional surgical myectomy and is potentially more attractive for patients with significant comorbidities that increase the risk of surgical myectomy, as the discomfort associated with surgery is avoided and the recovery time is reduced. RFCA is a novel method for relieving LVOTO, and preliminary result are promising; however, further clinical trials are still necessary. Gene therapy is also particularly attractive option for HCM, and the prospect of clinical therapy is on the horizon. New therapies that target the causes of HCM or slow the progression of the disease are urgently needed.

\section{REFERENCES}

1. Maron BJ, Ommen SR, Semsarian C, Spirito P, Olivotto I, Maron MS. Hypertrophic cardiomyopathy: present and future, with translation into contemporary cardiovascular medicine. J Am Coll Cardiol. (2014) 64:8399. doi: 10.1016/j.jacc.2014.05.003

2. Semsarian C, Ingles J, Maron MS, Maron BJ. New perspectives on the prevalence of hypertrophic cardiomyopathy. $J \mathrm{Am}$

\section{AUTHOR CONTRIBUTIONS}

GZC and $\mathrm{MH}$ conceived of the presented idea. JQ and YW developed the theory. MMH and GZC wrote the initial draft of the manuscript. All authors contributed to the article and approved the submitted version.

\section{FUNDING}

This work was supported by grant from the National Natural Science Foundation of China (No. 82070383).

Coll Cardiol. (2015) 65:1249-54. doi: 10.1016/j.jacc.2015. 01.019

3. Ommen SR, Mital S, Burke MA, Day SM, Deswal A, Elliott P, et al. AHA/ACC guideline for the diagnosis and treatment of patients with hypertrophic cardiomyopathy: executive summary: a report of the american college of cardiology/american heart association joint committee on clinical practice guidelines. Circulation. (2020) 142:e53357. doi: 10.1161/CIR.0000000000000938 
4. Maron MS, Maron BJ, Harrigan C, Buros J, Gibson CM, Olivotto I, et al. Hypertrophic cardiomyopathy phenotype revisited after 50 years with cardiovascular magnetic resonance. J Am Coll Cardiol. (2009) 54:2208. doi: 10.1016/j.jacc.2009.05.006

5. Maron MS, Olivotto I, Zenovich AG, Link MS, Pandian NG, Kuvin JT, et al. Hypertrophic cardiomyopathy is predominantly a disease of left ventricular outflow tract obstruction. Circulation. (2006) 114:22329. doi: 10.1161/CIRCULATIONAHA.106.644682

6. Kannappan M, Maron BJ, Rastegar H, Pandian NG, Maron MS, Rowin EJ. Underappreciated occurrence of discrete subaortic membranes producing left ventricular outflow obstruction in hypertrophic cardiomyopathy. Echocardiography. (2017) 34:1247-9. doi: 10.1111/echo.13577

7. Marian AJ, Braunwald E. Hypertrophic cardiomyopathy: genetics, pathogenesis, clinical manifestations, diagnosis, and therapy. Circ Res. (2017) 121:749-70. doi: 10.1161/CIRCRESAHA.117.311059

8. Maron BJ, Rowin EJ, Udelson JE, Maron MS. Clinical spectrum and management of heart failure in hypertrophic cardiomyopathy. JACC Heart Fail. (2018) 6:353-63. doi: 10.1016/j.jchf.2017.09.011

9. Dilaveris P, Aggeli C, Synetos A, Skiadas I, Antoniou CK, Tsiamis E, et al. Sustained ventricular tachycardia as a first manifestation of hypertrophic cardiomyopathy with mid-ventricular obstruction and apical aneurysm in an elderly female patient. Ann Noninvas Electrocardiol Offic J Int Soc Holter Noninvas Electrocardiol. (2017) 22:12422. doi: 10.1111/anec.12422

10. Corrado D, Basso C, Pavei A, Michieli P, Schiavon M, Thiene G. Trends in sudden cardiovascular death in young competitive athletes after implementation of a preparticipation screening program. Jama. (2006) 296:1593-601. doi: 10.1001/jama.296.13.1593

11. Belardinelli R, Georgiou D, Cianci G, Berman N, Ginzton L, Purcaro A. Exercise training improves left ventricular diastolic filling in patients with dilated cardiomyopathy. Clinic Prognost Impl Circul. (1995) 91:277584. doi: 10.1161/01.CIR.91.11.2775

12. Hambrecht $R$, Adams V, Erbs S, Linke A, Kränkel N, Shu Y, et al. Regular physical activity improves endothelial function in patients with coronary artery disease by increasing phosphorylation of endothelial nitric oxide synthase. Circulation. (2003) 107:31528. doi: 10.1161/01.CIR.0000074229.93804.5C

13. Saberi S, Wheeler M, Bragg-Gresham J, Hornsby W, Agarwal PP, Attili A, et al. Effect of moderate-intensity exercise training on peak oxygen consumption in patients with hypertrophic cardiomyopathy: a randomized clinical trial. Jama. (2017) 317:1349-57. doi: 10.1001/jama.2017.2503

14. Morrow AG, Reitz BA, Epstein SE, Henry WL, Conkle DM, Itscoitz SB, et al. Operative treatment in hypertrophic subaortic stenosis, techniques, and the results of pre and postoperative assessments in 83 patients Circulation. (1975) 52:88-102. doi: 10.1161/01.CIR.52.1.88

15. Song JK. Role of noninvasive imaging modalities to better understand the mechanism of left ventricular outflow tract obstruction and tailored lesionspecific treatment options. Circul J Offic J Japan Circul Soc. (2014) 78:180815. doi: 10.1253/circj.CJ-14-0524

16. Ommen SR, Maron BJ, Olivotto I, Maron MS, Cecchi F, Betocchi S, et al. Long-term effects of surgical septal myectomy on survival in patients with obstructive hypertrophic cardiomyopathy. J Am Coll Cardiol. (2005) 46:4706. doi: 10.1016/j.jacc.2005.02.090

17. Bogachev-Prokophiev A, Afanasyev A, Zheleznev S, Fomenko M, Sharifulin $\mathrm{R}$, Kretov E, et al. Mitral valve repair or replacement in hypertrophic obstructive cardiomyopathy: a prospective randomized study. Interact Cardiovasc Thorac Surg. (2017) 25:356-62. doi: 10.1093/icvts/ivx152

18. Dearani JA, Ommen SR, Gersh BJ, Schaff HV, Danielson GK. Surgery insight: septal myectomy for obstructive hypertrophic cardiomyopathy-the Mayo Clinic experience. Nat Clinic Pract Cardiovascul Med. (2007) 4:50312. doi: $10.1038 /$ ncpcardio0965

19. Maron BJ, Maron MS. The 20 advances that have defined contemporary hypertrophic cardiomyopathy. Trends Cardiovasc Med. (2015) 25:54-64. doi: 10.1016/j.tcm.2014. 09.004

20. Minakata K, Dearani JA, Nishimura RA, Maron BJ, Danielson GK. Extended septal myectomy for hypertrophic obstructive cardiomyopathy with anomalous mitral papillary muscles or chordae. J Thorac Cardiovasc Surg. (2004) 127:481-9. doi: 10.1016/j.jtcvs.2003.09.040
21. Maron BJ, Dearani JA, Ommen SR, Maron MS, Schaff HV, Gersh BJ, et al. The case for surgery in obstructive hypertrophic cardiomyopathy. J Am Coll Cardiol. (2004) 44:2044-53. doi: 10.1016/j.jacc.2004.04.063

22. Afanasyev A, Bogachev-Prokophiev A, Lenko E, Sharifulin R, Ovcharov M, Kozmin D, et al. Myectomy with mitral valve repair versus replacement in adult patients with hypertrophic obstructive cardiomyopathy: a systematic review and meta-analysis. Interact Cardiovasc Thorac Surg. (2019) 28:46572. doi: 10.1093/icvts/ivy269

23. Hong JH, Schaff HV, Nishimura RA, Abel MD, Dearani JA, Li Z, et al. Mitral regurgitation in patients with hypertrophic obstructive cardiomyopathy: implications for concomitant valve procedures. J Am Coll Cardiol. (2016) 68:1497-504. doi: 10.1016/j.jacc.2016.07.735

24. Kim LK, Swaminathan RV, Looser P, Minutello RM, Wong SC, Bergman $\mathrm{G}$, et al. Hospital volume outcomes after septal myectomy and alcohol septal ablation for treatment of obstructive hypertrophic cardiomyopathy: US nationwide inpatient database, 2003-2011. JAMA Cardiol. (2016) 1:32432. doi: 10.1001/jamacardio.2016.0252

25. Hong JH, Schaff HV, Nishimura RA. Fixed versus dynamic subaortic stenosis: Hemodynamics and resulting differences in Doppler echocardiography and aortic pressure contour. J Thorac Cardiovasc Surg. (2016) 151:8834. doi: 10.1016/j.jtcvs.2015.10.082

26. Goodwin JF, Oakley CM. Non-surgical myocardial reduction for hypertrophic obstructive cardiomyopathy. Lancet. (1995) 346:1624. doi: 10.1016/S0140-6736(95)91954-6

27. Gietzen FH, Leuner CJ, Obergassel L, Strunk-Mueller C, Kuhn H. Role of transcoronary ablation of septal hypertrophy in patients with hypertrophic cardiomyopathy, New York Heart Association functional class III or IV, and outflow obstruction only under provocable conditions. Circulation. (2002) 106:454-9. doi: 10.1161/01.CIR.0000022845.80802.9D

28. Afanasyev AV, Bogachev-Prokophiev AV, Kashtanov MG, Astapov DA, Zalesov AS, Budagaev SA, et al. Myectomy versus alcohol septal ablation in patients with hypertrophic obstructive cardiomyopathy. Interact Cardiovasc Thorac Surg. (2020) 31:158-65. doi: 10.1093/icvts/ivaa075

29. Bytyçi I, Nistri S, Mörner S, Henein MY. Alcohol septal ablation versus septal myectomy treatment of obstructive hypertrophic cardiomyopathy: a systematic review and meta-analysis. J Clinic Med. (2020) 9:10. doi: 10.3390/jcm9103062

30. Lemor A, Villablanca PA, Hosseini Dehkordi SH, Mand R, Hernandez GA, Jain $T$, et al. Comparison of outcomes of alcohol septal ablation or septal myectomy for hypertrophic cardiomyopathy in patients $\leq 65$ Years Versus $>65$ Years. Am J Cardiol. (2020) 127:128-34. doi: 10.1016/j.amjcard.2020.04.018

31. Chan W, Williams L, Kotowycz MA, Woo A, Rakowski H, Schwartz L, et al. Angiographic and echocardiographic correlates of suitable septal perforators for alcohol septal ablation in hypertrophic obstructive cardiomyopathy. Can J Cardiol. (2014) 30:912-9. doi: 10.1016/j.cjca.2014.04.008

32. Cooper RM, Shahzad A, McShane J, Stables RH. Alcohol septal ablation for hypertrophic obstructive cardiomyopathy: safe and apparently efficacious but does reporting of aggregate outcomes hide less-favorable results, experienced by a substantial proportion of patients? J Invasive Cardiol. (2015) 27:301-8.

33. Yanagiuchi T, Tada N, Haga Y, Suzuki S, Sakurai M, Taguri M, et al. Utility of preprocedural multidetector computed tomography in alcohol septal ablation for hypertrophic obstructive cardiomyopathy. Cardiovasc Interv Ther. (2019) 34:364-72. doi: 10.1007/s12928-019-00574-0

34. Nagueh SF, Groves BM, Schwartz L, Smith KM, Wang A, Bach RG, et al. Alcohol septal ablation for the treatment of hypertrophic obstructive cardiomyopathy. a multicenter north american registry. J Am Coll Cardio. (2011) 58:2322-8. doi: 10.1016/j.jacc.2011.06.073

35. Khouzam RN, Naidu SS. Current status and future perspectives on alcohol septal ablation for hypertrophic obstructive cardiomyopathy. Curr Cardiol Rep. (2014) 16:478. doi: 10.1007/s11886-014-0478-3

36. Liebregts M, Steggerda RC, Vriesendorp PA, van Velzen H, Schinkel AF, Willems R, et al. Long-term outcome of alcohol septal ablation for obstructive hypertrophic cardiomyopathy in the young and the elderly. JACC Cardiovascul Intervent. (2016) 9:463-9. doi: 10.1016/j.jcin.2015.11.036

37. Karimianpour A, Heizer J, Leaphart D, Rier JD, Shaji S, Ramakrishnan V, et al. Predicting complete heart block after alcohol septal ablation for hypertrophic cardiomyopathy using a risk stratification model and clinical tool. Catheteriz. 
Cardiovascul. Intervent. Offici. J. Soc. Cardiac Angiograph. Intervent. (2021) 29:478. doi: 10.1002/ccd.29478

38. Cooper RM, Shahzad A, Hasleton J, Digiovanni J, Hall MC, Todd DM, et al. Radiofrequency ablation of the interventricular septum to treat outflow tract gradients in hypertrophic obstructive cardiomyopathy: a novel use of CARTOSound ${ }^{\circledR}$ technology to guide ablation. Europace: European pacing, arrhythmias, and cardiac electrophysiology: journal of the working groups on cardiac pacing, arrhythmias, and cardiac cellular. Electrophysiol Euro Soc Cardiol. (2016) 18:113-20. doi: 10.1093/europace/euv302

39. Valeti US, Nishimura RA, Holmes DR, Araoz PA, Glockner JF, Breen JF, et al. Comparison of surgical septal myectomy and alcohol septal ablation with cardiac magnetic resonance imaging in patients with hypertrophic obstructive cardiomyopathy. J Am Coll Cardiol. (2007) 49:3507. doi: $10.1016 /$ j.jacc. 2006.08 .055

40. Vriesendorp PA, Liebregts M, Steggerda RC, Schinkel AF, Willems R, Ten Cate FJ, et al. Long-term outcomes after medical and invasive treatment in patients with hypertrophic cardiomyopathy. JACC Heart Fail. (2014) 2:6306. doi: 10.1016/j.jchf.2014.06.012

41. Bleszynski PA, Goldenberg I, Fernandez G, Howell E, Younis A, Chen AY, et al. Risk of arrhythmic events after alcohol septal ablation for hypertrophic cardiomyopathy using continuous implantable cardiac monitoring. Heart Rhyth. (2021) 18:50-6. doi: 10.1016/j.hrthm.2020.08.013

42. Veselka J, Jensen M, Liebregts M, Cooper RM, Januska J, Kashtanov M, et al. Alcohol septal ablation in patients with severe septal hypertrophy. Heart. (2020) 106:462-6. doi: 10.1136/heartjnl-2019-315422

43. Nakagawa H, Yamanashi WS, Pitha JV, Arruda M, Wang X, Ohtomo K, et al. Comparison of in vivo tissue temperature profile and lesion geometry for radiofrequency ablation with a saline-irrigated electrode versus temperature control in a canine thigh muscle preparation. Circulation. (1995) 91:226473. doi: $10.1161 / 01 . C I R .91 .8 .2264$

44. Ruffy R, Imran MA, Santel DJ, Wharton JM. Radiofrequency delivery through a cooled catheter tip allows the creation of larger endomyocardial lesions in the ovine heart. J Cardiovasc Electrophysiol. (1995) 6:108996. doi: 10.1111/j.1540-8167.1995.tb00386.x

45. Skrumeda LL, Mehra R. Comparison of standard and irrigated radiofrequency ablation in the canine ventricle. J Cardiovasc Electrophysiol. (1998) 9:1196205. doi: 10.1111/j.1540-8167.1998.tb00092.x

46. Nakagawa H, Wittkampf FH, Yamanashi WS, Pitha JV, Imai S, Campbell $\mathrm{B}$, et al. Inverse relationship between electrode size and lesion size during radiofrequency ablation with active electrode cooling. Circulation. (1998) 98:458-65. doi: 10.1161/01.CIR.98.5.458

47. Wittkampf FH, Nakagawa H, Foresti S, Aoyama H, Jackman WM. Salineirrigated radiofrequency ablation electrode with external cooling. J Cardiovasc Electrophysiol. (2005) 16:323-8. doi: 10.1046/j.1540-8167.2005.40629.x

48. Yan S, Wu X, Wang W. Theoretical and experimental analysis of amplitude control ablation and bipolar ablation in creating linear lesion and discrete lesions for treating atrial fibrillation. Int J Hyperther Offic J Euro Soc Hypertherm Oncol. (2017) 33:608-16. doi: 10.1080/02656736.2017.1286390

49. Lozekoot PW, de Jong MM, Parise O, Matteucci F, Lucà F, Kumar N, et al. The ABLA-BOX: an in vitro module of hybrid atrial fibrillation ablation. Innovations. (2016) 11:201-9. doi: 10.1177/155698451601100308

50. Lawrenz T, Kuhn H. Endocardial radiofrequency ablation of septal hypertrophy. a new catheter-based modality of gradient reduction in hypertrophic obstructive cardiomyopathy. Zeitschrift fur Kardiologie. (2004) 93:493-9. doi: 10.1007/s00392-004-0097-x

51. Lawrenz T, Borchert B, Leuner C, Bartelsmeier M, Reinhardt J, StrunkMueller C, et al. Endocardial radiofrequency ablation for hypertrophic obstructive cardiomyopathy: acute results and 6 months' follow-up in 19 patients. J Am Coll Cardiol. (2011) 57:572-6. doi: 10.1016/j.jacc.2010. 07.055

52. Emmel M, Sreeram N. Radiofrequency catheter septal ablation for hypertrophic obstructive cardiomyopathy in children. Netherlands heart journal: monthly journal of the Netherlands society of cardiology and the Netherlands. Heart Found. (2005) 13:448-51.

53. Shelke AB, Menon R, Kapadiya A, Yalagudri S, Saggu D, Nair S, et al. A novel approach in the use of radiofrequency catheter ablation of septal hypertrophy in hypertrophic obstructive cardiomyopathy. Indian Heart $\mathrm{J}$. (2016) 68:618-23. doi: 10.1016/j.ihj.2016.02.007
54. Crossen K, Jones M, Erikson C. Radiofrequency septal reduction in symptomatic hypertrophic obstructive cardiomyopathy. Heart Rhythm. (2016) 13:1885-90. doi: 10.1016/j.hrthm.2016.04.018

55. Maron MS, Olivotto I, Harrigan C, Appelbaum E, Gibson CM, Lesser JR, et al. Mitral valve abnormalities identified by cardiovascular magnetic resonance represent a primary phenotypic expression of hypertrophic cardiomyopathy. Circulation. (2011) 124:40-7. doi: 10.1161/CIRCULATIONAHA.110.985812

56. Sorajja P, Pedersen WA, Bae R, Lesser JR, Jay D, Lin D, et al. First experience with percutaneous mitral valve plication as primary therapy for symptomatic obstructive hypertrophic cardiomyopathy. J Am Coll Cardiol. (2016) 67:28118. doi: 10.1016/j.jacc.2016.03.587

57. Coylewright M, O’Neill ES, Robb JF, McCullough JN, Tighe CM, Callahan JM, et al. Reduction of left ventricular outflow tract obstruction with transcatheter mitral valve repair. Echocardiography. (2017) 34:6256. doi: 10.1111/echo. 13487

58. Adamczak DM, Oko-Sarnowska Z. Sudden cardiac death in hypertrophic cardiomyopathy. Cardiol Rev. (2018) 26:14551. doi: $10.1097 / C R D .0000000000000184$

59. Chan RH, Maron BJ, Olivotto I, Pencina MJ, Assenza GE, Haas T, et al. Prognostic value of quantitative contrast-enhanced cardiovascular magnetic resonance for the evaluation of sudden death risk in patients with hypertrophic cardiomyopathy. Circulation. (2014) 130:484-95. doi: 10.1161/CIRCULATIONAHA.113.007094

60. Rowin EJ, Maron BJ, Haas TS, Garberich RF, Wang W, Link MS, et al. Hypertrophic cardiomyopathy with left ventricular apical aneurysm: implications for risk stratification and management. J Am Coll Cardiol. (2017) 69:761-73. doi: 10.1016/j.jacc.2016.11.063

61. Maron BJ, Spirito P, Shen WK, Haas TS, Formisano F, Link MS, et al. Implantable cardioverter-defibrillators and prevention of sudden cardiac death in hypertrophic cardiomyopathy. JAMA. (2007) 298:40512. doi: 10.1001/jama.298.4.405

62. Maron BJ, Rowin EJ, Casey SA, Link MS, Lesser JR, Chan RH, et al. Hypertrophic cardiomyopathy in adulthood associated with low cardiovascular mortality with contemporary management strategies. J Am Coll Cardiol. (2015) 65:1915-28. doi: 10.1016/j.jacc.2015.02.061

63. Ruivo C, Montenegro Sá F, Correia J, Belo A, Loureiro MF, Morais J. The SHIFT model combines clinical, electrocardiographic and echocardiographic parameters to predict sudden cardiac death in hypertrophic cardiomyopathy. J Portug Soc Cardiol. (2019) 38:847-53. doi: 10.1016/j.repce.2019.05.025

64. Sen-Chowdhry S, Jacoby D, Moon JC, McKenna WJ. Update on hypertrophic cardiomyopathy and a guide to the guidelines. Nat Rev Cardiol. (2016) 13:651-75. doi: 10.1038/nrcardio.2016.140

65. Maron BJ, Casey SA, Chan RH, Garberich RF, Rowin EJ, Maron MS. Independent assessment of the European society of cardiology sudden death risk model for hypertrophic cardiomyopathy. Am J Cardiol. (2015) 116:75764. doi: 10.1016/j.amjcard.2015.05.047

66. O’Mahony C, Jichi F, Pavlou M, Monserrat L, Anastasakis A, Rapezzi C, et al. A novel clinical risk prediction model for sudden cardiac death in hypertrophic cardiomyopathy (HCM risk-SCD). Eur Heart J. (2014) 35:201020. doi: 10.1093/eurheartj/eht439

67. He D, Ye M, Zhang L, Jiang B. Prognostic significance of late gadolinium enhancement on cardiac magnetic resonance in patients with hypertrophic cardiomyopathy. Heart Lung: J Critic Care. (2018) 47:122-6. doi: 10.1016/j.hrtlng.2017.10.008

68. Elliott PM, Anastasakis A, Borger MA, Borggrefe M, Cecchi F, Charron P, et al. 2014 ESC Guidelines on diagnosis and management of hypertrophic cardiomyopathy: the task Force for the diagnosis and management of hypertrophic cardiomyopathy of the European society of cardiology (ESC). Eur Heart J. (2014) 35:2733-79. doi: 10.1093/eurheartj/ehu284

69. Maron BJ, Rowin EJ, Maron MS. Paradigm of sudden death prevention in hypertrophic cardiomyopathy. Circ Res. (2019) 125:370-8. doi: 10.1161/CIRCRESAHA.119.315159

70. Maron BJ, Maron MS. Contemporary strategies for risk stratification and prevention of sudden death with the implantable defibrillator in hypertrophic cardiomyopathy. Heart Rhyth. (2016) 13:115565. doi: 10.1016/j.hrthm.2015.12.048

71. Alfares AA, Kelly MA, McDermott G, Funke BH, Lebo MS, Baxter SB, et al. Results of clinical genetic testing of 2,912 probands with hypertrophic 
cardiomyopathy: expanded panels offer limited additional sensitivity. Genet Med Offic J Am Coll Med Genet. (2015) 17:880-8. doi: 10.1038/gim.2014.205

72. Marston S, Copeland O, Jacques A, Livesey K, Tsang V, McKenna WJ, et al. Evidence from human myectomy samples that MYBPC3 mutations cause hypertrophic cardiomyopathy through haploinsufficiency. Circ Res. (2009) 105:219-22. doi: 10.1161/CIRCRESAHA.109.202440

73. Bos JM, Towbin JA, Ackerman MJ. Diagnostic, prognostic, and therapeutic implications of genetic testing for hypertrophic cardiomyopathy. J Am Coll Cardiol. (2009) 54:201-11. doi: 10.1016/j.jacc.2009.02.075

74. Hershberger RE, Givertz MM, Ho CY, Judge DP, Kantor PF, McBride KL, et al. Genetic evaluation of cardiomyopathy: a clinical practice resource of the American college of medical genetics and genomics (ACMG). Genet Med Offic J Am Coll Med Genet. (2018) 20:899-909. doi: 10.1038/s41436-018-0039-z

75. Prondzynski M, Mearini G, Carrier L. Gene therapy strategies in the treatment of hypertrophic cardiomyopathy. Pflugers Archiv: Euro J Physiol. (2019) 471:807-15. doi: 10.1007/s00424-018-2173-5

76. Ingles J, Goldstein J, Thaxton C, Caleshu C, Corty EW, Crowley SB, et al. Evaluating the clinical validity of hypertrophic cardiomyopathy genes. Circul Genom Precis Med. (2019) 12:e002460. doi: 10.1161/CIRCGEN.119.002460

77. Kolokotronis K, Kühnisch J, Klopocki E, Dartsch J, Rost S, Huculak C, et al. Biallelic mutation in MYH7 and MYBPC3 leads to severe cardiomyopathy with left ventricular noncompaction phenotype. Hum Mutat. (2019) 40:110114. doi: 10.1002/humu. 23757

78. Ingles $\mathrm{J}$, Burns $\mathrm{C}$, Bagnall $\mathrm{RD}$, Lam $\mathrm{L}$, Yeates $\mathrm{L}$, Sarina $\mathrm{T}$ et al. Nonfamilial Hypertrophic Cardiomyopathy: Prevalence, Natural History, and Clinical Implications. Circul. Cardiovascul. Genet. (2017) 10:1620. doi: 10.1161/CIRCGENETICS.116.001620

79. Amano Y, Kitamura M, Takano H, Yanagisawa F, Tachi M, Suzuki Y, et al. Cardiac MR imaging of hypertrophic cardiomyopathy: techniques, findings, and clinical relevance. Offic J Japan Soc Magn Resonan Med. (2018) 17:12031. doi: 10.2463/mrms.rev.2017-0145

80. van Velzen HG, Schinkel AFL, Oldenburg RA, van Slegtenhorst MA, FrohnMulder IME, van der Velden J. et al. Clinical characteristics and long-term outcome of hypertrophic cardiomyopathy in individuals with a MYBPC3 (Myosin-Binding Protein C) Founder Mutation. Circul Cardiovascul Gene. (2017) 10:1660. doi: 10.1161/CIRCGENETICS.116.001660

81. Teekakirikul P, Zhu W, Huang HC, Fung E. Hypertrophic cardiomyopathy: an overview of genetics and management. Biomolecules. (2019) 9:878. doi: 10.3390/biom 9120878

82. Semsarian C, Semsarian CR. Variable penetrance in hypertrophic cardiomyopathy: in search of the holy grail. J Am Coll Cardiol. (2020) 76:560-2. doi: 10.1016/j.jacc.2020.06.023

83. Ko C, Arscott P, Concannon M, Saberi S, Day SM, Yashar BM, et al. Genetic testing impacts the utility of prospective familial screening in hypertrophic cardiomyopathy through identification of a nonfamilial subgroup. Genet Med Offic J Am Coll Med Genetic. (2018) 20:69-75. doi: 10.1038/gim.2017.79

84. Lopes LR, Brito D, Belo A, Cardim N. Genetic characterization and genotype-phenotype associations in a large cohort of patients with hypertrophic cardiomyopathy-an ancillary study of the Portuguese registry of hypertrophic cardiomyopathy. Int J Cardiol. (2019) 278:173-9. doi: 10.1016/j.ijcard.2018.12.012

85. Kolokotronis K, Pluta N, Klopocki E, Kunstmann E, Messroghli D, Maack C, et al. New insights on genetic diagnostics in cardiomyopathy and arrhythmia patients gained by stepwise exome data analysis. J Clinic Med. (2020) 9:1628. doi: $10.3390 / \mathrm{jcm} 9072168$

86. Sawyer SL, Hartley T, Dyment DA, Beaulieu CL, Schwartzentruber J, Smith A, et al. Utility of whole-exome sequencing for those near the end of the diagnostic odyssey: time to address gaps in care. Clin Genet. (2016) 89:27584. doi: $10.1111 /$ cge. 12654

87. Mogensen J, van Tintelen JP, Fokstuen S, Elliott P, van Langen IM, Meder B, et al. The current role of next-generation DNA sequencing in routine care of patients with hereditary cardiovascular conditions: a viewpoint paper of the European Society of Cardiology working group on myocardial and pericardial diseases and members of the European Society of Human Genetics. Eur Heart J. (2015) 36:1367-70. doi: 10.1093/eurheartj/ehv122
88. Hershberger RE, Givertz MM, Ho CY, Judge DP, Kantor PF, McBride KL, et al. Genetic evaluation of cardiomyopathy-a heart failure society of America practice guideline. J Card Fail. (2018) 24:281-302. doi: 10.1016/j.cardfail.2018.03.004

89. Lorenzini M, Norrish G, Field E, Ochoa JP, Cicerchia M, Akhtar MM, et al. Penetrance of hypertrophic cardiomyopathy in sarcomere protein mutation carriers. J Am Coll Cardiol. (2020) 76:550-9. doi: 10.1016/j.jacc.2020.06.011

90. Bagnall RD, Ingles J, Dinger ME, Cowley MJ, Ross SB, Minoche AE, et al. Whole genome sequencing improves outcomes of genetic testing in patients with hypertrophic cardiomyopathy. J Am Coll Cardiol. (2018) 72:41929. doi: 10.1016/j.jacc.2018.04.078

91. Gómez Arraiz I, Barrio Ollero E, Gómez Peligros A. Genetic tests in hypertrophic cardiomyopathy: benefits, limitations, and applications in clinical practice. Semergen. (2018) 44:48591. doi: 10.1016/j.semerg.2018.03.002

92. Burns C, Bagnall RD, Lam L, Semsarian C, Ingles J. Multiple gene variants in hypertrophic cardiomyopathy in the era of next-generation sequencing. Circul Cardiovascul Genet. (2017) 10:1666. doi: 10.1161/CIRCGENETICS.116.001666

93. Fourey D, Care M, Siminovitch KA, Weissler-Snir A, Hindieh W, Chan RH, et al. Prevalence and clinical implication of double mutations in hypertrophic cardiomyopathy: revisiting the gene-dose effect. Circul Cardiovascul Genet. (2017) 10:1685. doi: 10.1161/CIRCGENETICS.116.001685

94. Vermeer AMC, Clur SB, Blom NA, Wilde AAM, Christiaans I. Penetrance of hypertrophic cardiomyopathy in children who are mutation positive. $J$ Pediatr. (2017) 188:91-5. doi: 10.1016/j.jpeds.2017.03.033

95. Semsarian C, Ho CY. Screening children at risk for hypertrophic cardiomyopathy: balancing benefits and harms. Eur Heart J. (2019) 40:36824. doi: 10.1093/eurheartj/ehz487

96. Monteiro da. Rocha A, Guerrero-Serna G, Helms A, Luzod C, Mironov S, Russell M, et al. Deficient cMyBP-C protein expression during cardiomyocyte differentiation underlies human hypertrophic cardiomyopathy cellular phenotypes in disease specific human ES cell derived cardiomyocytes. J Mol Cell Cardiol. (2016) 99:197-206. doi: 10.1016/j.yjmcc.2016.09.004

97. Jessup M, Greenberg B, Mancini D, Cappola T, Pauly DF, Jaski B, et al. Calcium Upregulation by Percutaneous Administration of Gene Therapy in Cardiac Disease (CUPID): a phase 2 trial of intracoronary gene therapy of sarcoplasmic reticulum Ca2+ATPase in patients with advanced heart failure. Circulation. (2011) 124:304-13. doi: 10.1161/CIRCULATIONAHA.111.022889

98. Ben Jehuda R, Eisen B, Shemer Y, Mekies LN, Szantai A, Reiter I, et al. CRISPR correction of the PRKAG2 gene mutation in the patient's induced pluripotent stem cell-derived cardiomyocytes eliminates electrophysiological and structural abnormalities. Heart rhythm. (2018) 15:267-76. doi: 10.1016/j.hrthm.2017. 09.024

Conflict of Interest: The authors declare that the research was conducted in the absence of any commercial or financial relationships that could be construed as a potential conflict of interest.

Publisher's Note: All claims expressed in this article are solely those of the authors and do not necessarily represent those of their affiliated organizations, or those of the publisher, the editors and the reviewers. Any product that may be evaluated in this article, or claim that may be made by its manufacturer, is not guaranteed or endorsed by the publisher.

Copyright $\odot 2021 \mathrm{He}$, Qiu, Bai, Wang, Hu and Chen. This is an open-access article distributed under the terms of the Creative Commons Attribution License (CC BY). The use, distribution or reproduction in other forums is permitted, provided the original author(s) and the copyright owner(s) are credited and that the original publication in this journal is cited, in accordance with accepted academic practice. No use, distribution or reproduction is permitted which does not comply with these terms. 